Dicle Tıp Dergisi / Dicle Med J (2019) 46 (4) : 743 - 749

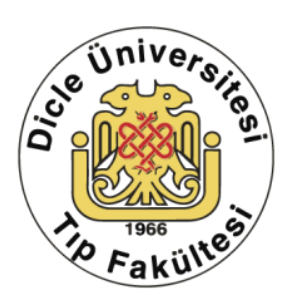

WWW.diclemedj.org

Özgün Araștırma / Original Article

\title{
Solid Organ Transplantasyonu Sonrası Post-Transplant Lenfoproliferatif Hastalıklar: Tek Merkez Deneyimi
}

\author{
Eren Arslan Davulcu' ${ }^{1}$, Hale Bülbül2 ${ }^{2}$, Yusuf Ulusoy3 ${ }^{3}$, Nur Akad Soyer ${ }^{4}$, \\ Derya Demir'5, Nazan Özsan ${ }^{6}$, Güneș Ak ${ }^{7}$, Fahri Şahin' ${ }^{8}$, Mahmut Töbü 9 , \\ Murat Tombuloğlu10, Filiz Vural11, Güray Saydam ${ }^{12}$
}

1 Ege Üniversitesi Tıp Fakültesi Hematoloji Bilim Dalı, Bornova, İzmir, Türkiye ORCID: 0000-0001-9262-2883 2 Ege Üniversitesi Tıp Fakültesi Hematoloji Bilim Dal, Bornova, İzmir, Türkiye ORCID: 0000-0001-5333-8679

3 Ege Üniversitesi Tıp Fakültesi Hematoloji Bilim Dal, Bornova, İzmir, Türkiye ORCID: 0000-0002-4408-3544

4 Ege Üniversitesi Tıp Fakültesi Hematoloji Bilim Dal, Bornova, İzmir, Türkiye ORCID: 0000-0002-7722-506X

5 Ege Üniversitesi Tıp Fakültesi Patoloji Anabilim Dal, Bornova, İzmir, Türkiye ORCID: 0000-0002-6333-8856

6 Ege Üniversitesi Tıp Fakültesi Patoloji Anabilim Dal, Bornova, İzmir, Türkiye ORCID: 0000-0001-7844-972X

7 Ege Üniversitesi Tıp Fakültesi Klinik Biyokimya Bilim Dalı, Bornova, İzmir, Türkiye ORCID: 0000-0001-6780-1812

8 Ege Üniversitesi Tıp Fakültesi Hematoloji Bilim Dalı, Bornova, İzmir, Türkiye ORCID: 0000-0001-9315-8891

9 Ege Üniversitesi Tıp Fakültesi Hematoloji Bilim Dalı, Bornova, İzmir, Türkiye ORCID: 0000-0001-5939-4989

10 Ege Üniversitesi Tıp Fakültesi Hematoloji Bilim Dall, Bornova, İmir, Türkiye ORCID: 0000-0002-8340-7476

11 Ege Üniversitesi Tıp Fakültesi Hematoloji Bilim Dalı, Bornova, İzmir, Türkiye ORCID: 0000-0003-3489-296X

12 Ege Üniversitesi Tıp Fakültesi Hematoloji Bilim Dall, Bornova, İzmir, Türkiye ORCID: 0000-0001-8646-1673

Geliş: 19.06.2019; Revizyon: 31.07.2019; Kabul Tarihi: 07.08.2019

Öz

Amaç: Kliniğimizde solid organ transplantasyonu sonrası post-transplant lenfoproliferatif hastalık tanısı almış hastaların klinik bulgularını, laboratuar özelliklerini, genel ve progesyonsuz sağ kalımlarını değerlendirmeyi amaçladık.

Yöntemler: Ocak 2000- Aralık 2018 yılları arasında solid organ transplantasynu sonrası post-transplant lenfoproliferatif hastalık tanısı alan hastalar retrospektif olarak incelendi. Hastaların cinsiyeti, transplantasyon oldukları yaş, lenfoproliferatif hastalık tanı yaşı, transplantasyon sonrası lenfoproliferatif hastalık tanısına kadar geçen süre, lenfoproliferatif hastalık için klinik prezentasyonları, tümör karakteristikleri, tanı anındaki laktat dehidrogenaz düzeyleri, immunsupresif tedavileri, lenfoproliferatif hastalık için aldıkları tedaviler ve bu tedavilere yanıtları, toplam ve olaysız sağ kalım değerlendirildi. 
Bulgular: On hastaya post-transplant lenfoproliferatif hastalık tanısı konmuştur. Hastaların 8'i böbrek, 2'si karaciğer transplantasyonu sonrası lenfoproliferatif hastalık tanısı almışlardır. 8 hastaya diffüz büyük B hücreli lenfoma, 2 hastaya toplam 3 kere Hodgkin lenfoma (1 hasta nüks etmiştir) tanısı konmuştur. 5 yıllık sağ kalım \%90 \pm 9 ve olaysız sağ kalım 150,76 $\pm 13,28$ ay bulunmuştur.

Sonuç: Erken dönemde septik nedenlerle kaybedilen bir hasta dışındaki hastalar hayatta ve remisyondadır. Çalışmamızın 5 yıllık sağ kalım oranının literatürde bildirilen birçok çalışmadan daha uzun olması tedavi başarısını göstermektedir.

Anahtar kelimeler: Organ transplantasyonu, lenfoma non-Hodgkin, Hodgkin hastalığı, tedavi

\title{
Post-Transplant Lymphoproliferative Diseases After Solid Organ Transplantation: Single Center Experience
}

\begin{abstract}
Objective: We aimed to evaluate the clinical findings, laboratory features, general and progression free survival of the patients diagnosed with post-transplant lymphoproliferative disease in our clinic.

Method: Patients who were diagnosed with post-transplant lymphoproliferative disease after solid organ transplantation between January 2000 and December 2018 were retrospectively analysed. Age of patients, age of transplantation, age of diagnosis of lymphoproliferative disease, time until diagnosis of lymphoproliferative disease after transplantation, clinical presentations for lymphoproliferative disease, tumor characteristics, lactate dehydrogenase levels at diagnosis, immunosuppressive therapies, treatments for lymphoproliferative disease and their responses to these therapies, overall and progression free survival were evaluated.

Results: 10 patients were diagnosed with post-transplant lymphoproliferative disease in our clinic. Eight of the patients were diagnosed as lymphoproliferative disease after kidney transplantation and 2 patients after liver transplantation. 8 patients were diagnosed with diffuse large B-cell lymphoma, 2 patients were diagnosed with Hodgkin's lymphoma 3 times (1 patient relapsed). 5-year survival was $90 \pm 9 \%$ and event-free survival was $150.76 \pm$ 13.28 months.

Conclusion: Patients are in remission and alive except one patient who died because of septic complications in early transplant period. The 5-year survival rate of our study is longer than the many studies reported in the literature and it shows the success of the treatment.
\end{abstract}

Keywords: Organ transplantation, lymphoma non-Hodghin, Hodgkin disease, treatment.

\section{GíRiş}

Post-transplant lenfoproliferatif hastalıklar (PTLH) solid organ ya da hematopoetik kök hücre transplantasyonu sonrası görülen lenfoid ya da plazmasitik proliferasyonlardır. PTLH, solid organ transplantasyonu (SOT) sonrasinda non-melanom cilt kanseri ve insitu servikal kanserin dışında en sık görülen malignitedir ${ }^{1}$. Sıklığı çeşitli faktörlere ve SOT'un yapıldığı merkezlerin verilerine göre değişmekle birlikte ince barsak ve çoklu organ alıcılarında \%5-20, akciğer ve kalp alıcılarında \%2-10, böbrek ve karaciğer alıcılarında ise \%1-5'tir². Başlıca risk faktörleri arasında transplantasyonun şekli, hastanın yaşı, immunsupresif tedavisi ve süresi, Ebstein-Barr virüs (EBV) serolojisi yer almaktadır $^{3}$. Çocuklar PTLH gelişim için risk altındadır çünkü genellikle EBV açısından seronegatiftirler. Anti timosit globulin (ATG), OKT3 gibi $\mathrm{T}$ hücre fonksiyonunu baskılayan ilaçlar, özellikle diğer immunsupresiflerle kombinasyon halinde ve uzun süre kullanıldığında PTLH riskini arttırır ${ }^{4}$. EBV naiv hastalar, EBV enfeksiyonunu seropozitif 
donörden alırlar ve transplantasyon sonrasında EBV'ye özel sitotoksik $T$ lenfosit yanıtını başlatamadıkları için PTLH açısından yüksek risk altındadırlar ${ }^{5,6}$. Transplant öncesi EBV ile karşılaşmamış olmak, hala en önemli risk faktörüdür. PTLH, SOT sonrası herhangi bir dönemde görülebilmektedir.

PTLH'nin güncel sinıflaması, Dünya Sağlık Örgütü'nün 2017 yılında yayımladığı Hematopoetik ve Lenfoid Doku Tümörlerin Sinıflandırılmasına dayanmaktadır ${ }^{7}$. Buna göre bir spektrum şeklinde de değerlendirilebilen hastalık destrüktif olmayan PTLH, polimorfik PTLH, monomorfik PTLH ve Hodgkin lenfoma tipi PTLH olarak 4 ana başlığa ayrılır. Destrüktif olmayan PTLH'nin plazmasitik hiperplazi, enfeksiyöz mononükleoz benzeri lezyonlar ve florid foliküler hiperplaziden oluşan üç türü vardır. Spektrumun bir ucudur. Bu lezyonlar spontan olarak veya immünsupressif tedavinin azaltılması ile düzelebilmektedir ${ }^{3}$. Polimorfik PTLH'de, B hücreli ya da T/NK hücreli lenfomaların tüm kriterlerini karşılamamakla birlikte malign transformasyonu destekleyen poliklonal ya da monoklonal lenfoid infiltratlar izlenmektedir. Monomorfik PTLH, lenfomalar gibi sinıflandırılır. Hem $B$ hem de $T$ lenfositlerden kaynaklanmakta, dokunun yapısı bozulmakta ve diğer organlara yayllım göstermektedir. Küçük B hücreli lenfomalar (foliküler lenfoma, küçük lenfositik lenfoma) ve marjinal zon lenfomalar bu gruba girmez ${ }^{4}$. Hodgkin lenfoma tipi PTLH en nadir görülen türüdür.

Tedavi transplantın çeşidine, PTLH'nin tipine ve hastanın takip edildiği merkeze göre değişmektedir. Erken lezyonlarda immunsupresyonun azaltılması ya da kesilmesi etkili oluyor iken, polimorfik ve monomorfik PTLH'de hastalığın özelliğine göre immunsupresyonun azaltılmasina ek olarak tek başına rituksimab (CD 20 pozitif ise), CHOP benzeri kemoterapiler ve radyoterapi yapılabilmektedir. Hodgkin lenfoma tipinde ise immunsupresyonda azaltmaya ek olarak bu lenfomaya özel tedavi ajanları kullanılabilir8-10.

Genel sağ kalım oranları PTLH'nin tipi, yaygınlığı, tedavi ve çalışmanın yapıldığı zaman (rituksimab öncesi/sonrası) gibi başlıca faktörlerden etkilenmekle birlikte 3 yıllık ortalama \%49- 6211,12, 5 ylllk ortalama \%42

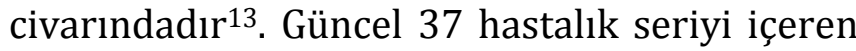
bir çalışmada ise erken başlangıçlı PTLH'lerin 2 yıllık sağ kalımları \%100 ve geç başlangıçlı PTLH'lerin 1 ve 2 yıllık sağ kalımları sırası ile \%71,4 ve \%67,9 bulunmuştur. Erken başlangıç, renal transplant sonrası ilk bir yıl içinde ortaya çıkan hastalık olarak tanımlanmış, diğerleri geç başlangıçlı olarak değerlendirilmiştir ${ }^{14}$.

\section{AMAÇ}

Çalışmanın amacı, Ege Üniversitesi Hematoloji Kliniğinde Ocak 2000 ve Aralık 2018 yılları arasında PTLH tanısı almış hastaların klinik, patolojik ve laboratuvar özelliklerini incelemek, aldıkları tedavi yöntemlerini, bu tedavilere yanıtlarını, varsa yan etkilerini değerlendirmek, genel ve olaysız sağ kalımı hesaplamaktır.

\section{YÖNTEMLER}

Ege Üniversitesi Hematoloji kliniğinde Ocak 2000- Aralık 2018 yılları arasinda SOT sonrası PTLH tanisı alan hastalar retrospektif olarak incelendi. Hastaların cinsiyeti, SOT oldukları yaş, PTLH tanı yaşı, SOT sonrası PTLH tanısına kadar geçen süre, PTLH için klinik prezentasyonları, tümör karakteristikleri, tanı anındaki laktat dehidrogenaz (LDH) düzeyleri, immunsupresif tedavileri, PTLH için aldıkları tedaviler ve bu tedavilere yanitları, toplam ve olaysız sağ kalım değerlendirildi. PTLH tedavisi için yanıt değerlendirilmesi tedavi bitiminden sonra çekilen PET-BT ve bunu izleyen takiplerindeki fizik muayene, laboratuvar, ultrasonografi ve bilgisayarlı tomografi bulgularına göre yapıldı. Tam yanıt tümöre ait bulguların tamamen kaybolduğu, parsiyel yanit tümör boyutunda en az \%50 azalmanın olduğu, stabil hastalık tümör boyutlarının değişmediği 
ve progresif hastalık ise tümör boyutlarının arttığı ya da yeni lezyonların ortaya çıktığı durum olarak değerlendirildi ${ }^{15}$.

Toplam sağ kalım, tanı anından hastanın son görüldüğü tarihe kadar geçen zaman olarak alındı. Olaysız sağ kalım hesaplanırken ölüm ve hastalık nüksü olay olarak kabul edildi. Toplam ve olaysız sağ kalım Kaplan-Meier analizi ile hesaplandi.

Çalışmamız Ege Üniversitesi tıbbi araştırmalar etik kurulu tarafından 02.05.2019 tarihinde ve 19-5T/39 karar numarası ile onaylanmıștır. Çalışmamız Helsinki Deklarasyonu prensiplerine uygundur ve hastalardan (bir hasta için hastanın birinci derece yakınından) bilgilendirilmiş olur (rıza) formu alınmıștır.

\section{BULGULAR}

On sekiz yıl içinde, kliniğimizde 10 hastaya, toplam 11 adet PTLH tanısı kondu. Hastalardan biri SOT sonrası 120. ayda Hodgkin lenfoma nodüler sklerozan tip tanısı aldı. Aynı hasta 252. ayda nüks ettiği için bu PTLH'ler iki ayrı olay olarak değerlendirildi.

Hastaların SOT sırasında medyan yaşı 27 (9-58 yaş), PTLH tanısı anında ise 30 bulundu (17-62 yaş).

Hastaların 8'inde $(\% 72,7)$ monomorfik PTLH (hepsi diffüz büyük B hücreli lenfoma [DBBHL] tipinde), 3'ünde $(\% 27,3)$ Hodgkin lenfoma (HL) nodüler sklerozan tip PTLH (1 hastada 2 kere) saptandl. Böbrek transplantasynu olan 8 hastanın 7'sinde DBBHL, 1'inde HL; karaciğer transplantasyonu olan 2 hastanın 1'inde DBBHL, 1'inde HL saptandı.

Transplantasyon sonrası medyan PTLH ortaya çıma süresi 48 aydı (12-252 ay).

PTLH zamanlaması açısından değerlendirildiğinde erken başlangıç $(<1$ yıl $)$ hiçbir hastada görülmez iken, geç ( $>1$ yil) 7 hastada, çok geç (>10 yıl) 4 hastada görüldü.

Hastaların hepsi farklı dozlar ve kombinasyonlar halinde immunsupresif tedaviler almaktaydı. İmmunsupresif ilaçlar arasında prednizolon, siklosporin, mikofenolat mofetil, takrolimus, everolimus ve sirolimus vardı. Patoloji preparatlarına ulaşılabilen 7 hastada EBER (Epstein-Barr Virus-Encoded Small RNAs) bakılmış, HL tanılı her 2 hastada da negatif, DBBHL tanılı 5 hastanın 4'ünde pozitif bulunmuştu. Sadece iki hastanın EBV serolojisine ulaşılabildi. Bu iki hastada da EBV VCA IgG ve anti EBNA pozitif bulundu.

Ekstranodal hastalık ile 5 DBBHL hastasında karşılaşıldı (\%50). Bunların ikisi intrakranial tutulum, biri transplante böbrek, biri tiroid ve bir diğeri de akciğer tutulumuydu. Hastaların klinik özellikleri tablo I'de özetlenmiștir.

PTLH tanısı alan hastaların tedavisinde ilk adım immunsupresif tedaviyi azaltmak, mümkünse kesmek oldu. DBBHL tanılı hastaların hepsi 6-8 kür arasında rituksimab tedavisi aldı. Hastalık evresi, hastanın performans durumu ve komorbiditeleri göz önüne alınarak bazı hastalara CHOP kemoterapisi eklendi. İntrakranial DBBHL'si olan bir hastaya 6 kür rituksimab sonrası konsolidatif amaçlı kranial radyoterapi yapıldı. İntrakranial DBBHL tanılı bir diğer hasta ise R-IDARAM kemoterapisinin 20. gününde nötropenik ateşi takip eden sepsis nedeniyle kaybedildi. HL tanılı 2 hasta ABVD kemoterapisi aldı. Evre 2B olan hastaya ABVD sonrası mediastinal düşük FDG tutulumlu lenf nodu kalması nedeniyle ayrıca mediastinal radyoterapi de yapıldı.

Kliniğimizde PTLH tanısıyla takipli hastaların \%90'ı hayatta ve tam yanitlı olarak izlenmektedir. Tedavi sonrası medyan takip süresi 44 aydır (14-157 ay). Genel sağ kalıma ulaşılamadı. 5 yıllık sağ kalım $\% 90 \pm 9$ ve olaysız sağ kalım ortalama $150,76 \pm 13,28$ ay bulundu. Kaybedilen tek hasta, takip periyodunun erken döneminde öldüğü için sağ kalım grafiği elde edilemedi. 
Tablo I: Hastaların klinik özellikleri

\begin{tabular}{|c|c|c|c|c|c|c|c|c|c|c|}
\hline Hasta & Cinsiyet & $\begin{array}{c}\text { PTLH } \\
\text { tanı yaşı }\end{array}$ & $\begin{array}{l}\text { PTLH } \\
\text { türü }\end{array}$ & Tutulum yeri/yerleri & $\begin{array}{c}\text { LDH } \\
\text { (U/L) } \\
\text { (Ref.) }\end{array}$ & Evre & $\begin{array}{c}\text { Transplante } \\
\text { organ }\end{array}$ & $\begin{array}{l}\text { Transplant-PTLH } \\
\text { arası süre (ay) }\end{array}$ & $\begin{array}{l}\text { Tedavisi ve } \\
\text { kür sayısı }\end{array}$ & $\begin{array}{c}\text { Tedaviye } \\
\text { yanıt }\end{array}$ \\
\hline 1 & $\mathrm{E}$ & 43 & DBBHL & Akciğer & $\begin{array}{l}252 \\
(135- \\
225)\end{array}$ & $1 \mathrm{E}$ & Böbrek & 156 & $\begin{array}{c}\text { RCHOPx6+ } \\
\text { Rx2 }\end{array}$ & TY \\
\hline 2 & $\mathrm{E}$ & 36 & DBBHL & $\begin{array}{l}\text { Servikal ve aksiller } \\
\text { lenf nodu }\end{array}$ & $\begin{array}{c}899 \\
(240- \\
480)\end{array}$ & $2 \mathrm{~A}$ & Böbrek & 22 & $\mathrm{Rx} 8$ & TY \\
\hline 3 & $\mathrm{E}$ & 17 & DBBHL & Transplante böbrek & $\begin{array}{c}773 \\
(230- \\
460)\end{array}$ & $1 \mathrm{E}$ & Böbrek & 24 & R-CHOPx6 & TY \\
\hline 4 & $\mathrm{E}$ & 38 & DBBHL & $\begin{array}{l}\text { Toraks ve batında } \\
\text { lenf nodu }\end{array}$ & $\begin{array}{c}642 \\
(240- \\
480)\end{array}$ & $3 B$ & Karaciğer & 120 & $\mathrm{Rx} 8$ & TY \\
\hline 5 & K & 26 & DBBHL & Batın içi lenf nodu & $\begin{array}{c}\mathbf{5 6 5} \\
(240- \\
480)\end{array}$ & $1 \mathrm{~A}$ & Böbrek & 24 & $\mathrm{Rx} 7$ & TY \\
\hline 6 & $\mathrm{E}$ & 18 & DBBHL & İntrakranial & $\begin{array}{c}375 \\
(240- \\
480)\end{array}$ & $1 \mathrm{E}$ & Böbrek & 12 & $\begin{array}{c}\text { Rx6+ } \\
\text { RT }\end{array}$ & TY \\
\hline 7 & K & 62 & DBBHL & Tiroid, mediasten & $\begin{array}{c}287 \\
(135- \\
225)\end{array}$ & $4 \mathrm{~B}$ & Böbrek & 48 & R-CHOPx6 & TY \\
\hline 8 & $\mathrm{E}$ & 43 & DBBHL & İntrakranial & $\begin{array}{l}\mathbf{2 8 7} \\
(135- \\
225) \\
\end{array}$ & $1 \mathrm{E}$ & Böbrek & 60 & $\begin{array}{c}\mathrm{R}- \\
\text { İDARAMx1 }\end{array}$ & - \\
\hline 9 & $\mathrm{E}$ & 28 & HL, NS & $\begin{array}{l}\text { Servikal, aksiller, } \\
\text { mediastinel LAP }\end{array}$ & $\begin{array}{c}343 \\
(135- \\
225) \\
\end{array}$ & $2 \mathrm{~B}$ & Böbrek & 24 & $\begin{array}{l}\text { ABVDx 4+ } \\
\text { RT }\end{array}$ & TY \\
\hline 10 & K & $\begin{array}{l}19, \\
30\end{array}$ & HL, NS & Aksilla,boyun & $\begin{array}{c}205 \\
(135- \\
225)\end{array}$ & $2 \mathrm{~A}$ & Karaciğer & $\begin{array}{l}120 \\
252\end{array}$ & $\begin{array}{c}\text { İlk tedavi } \\
\text { bilinmiyor } \\
\text { ABVDx3 }\end{array}$ & $\begin{array}{l}\text { TY } \\
\text { TY }\end{array}$ \\
\hline
\end{tabular}

K: Kadın, E: Erkek, DBBHL: Diffüz büyük B hücreli lenfoma, HL: Hodgkin lenfoma, NS: nodüler sklerozan, LDH: Laktat dehidrogenaz, ref.: Referans aralığı, PTLH: Post-transplant lenfoproliferatif hastalık, R: Ritüksimab, CHOP: siklofosfamid- doksosubisin-vinkristinmetilprednizolon, R-IDARAM: Rituksimab-idarubisin-dekzametazon-sitozin arabinozid-methotreksat, ABVD: Doksorubisinbleomisin-vinblastin-dakarbazin, RT: Radyoterapi, TY: Tam yanıt

\section{TARTIŞMA ve SONUÇ}

Çalışmamızda, erişkin hematoloji kliniğinde PTLH tanısı alan ve tedavisi yapilan hastalar değerlendirilmiştir. Kliniğimizin PTLH tanı medyan yașı olan 30 bazı çalıșmalara göre daha genç bir popülasyonu göstermekle birlikte, diğer çalıșmalara benzer olarak sıklığı erkek bireylerde daha fazla olmuştur ${ }^{12,13}$.

Böbrek transplantasyonu sonrası 8 hastada PTLH gelişmiştir. Bunların 7'si DBBHL, 1'i HL türünde olmuştur. PTLH görülme süresi medyan 24 ay olmakla birlikte, erken başlangıçlı hastalık (<1 yll) 1 hastada $(\% 12,5)$, geç hastalık (>1 yıl) 7 hastada (\%75), çok geç hastalık $(>10 \quad$ yll $) \quad 1$ hastada $\quad(\% 12,5)$ görülmüştür. $\mathrm{Bu}$ dağılım 80 hastalık renal transplantasyon sonrası PTLH serisinin verilerine paralellik göstermektedir ${ }^{16}$.

Bir hastada transplante edilen böbrekte, SOT'nin 24. ayında DBBHL (evre 1E) saptanmıștır. Tanı biyopsi ile konduğu için, graftektomiye gerek kalmamıștır. Hasta 6 kür R-CHOP kemoterapisi sonrası remisyonda izlenmektedir. Literatürde de transplante edilen böbrekte gelişen PTLH örnekleri vardır17-19. Hatta graft PTLH'nin daha iyi prognoza sahip olduğu bildirilmektedir. Caillard ve ark. bu durumu transplante edilen 
organın yakın takibine, dolayısıyla erken teşhise ve cerrahi eksizyon yapmak için organa ulaşmanın kolay olmasına bağlamaktadır ${ }^{18}$.

SOT sonrası primer santral sinir sistemi lenfoması olan 34 hastanın değerlendirildiği bir çalışmada hastaların çoğunun B hücre kökenli olduğu, multipl parankimal lezyon oluşturduğu ve medyan sağ kalım 47 ay olduğu bulunmuştur. SOT-PTLH arası süre medyan 4,4 yıldır. Hastaların yaklaşık yarısı böbrek transplantasyonu sonrası PTLH olmuştur. Tedavi seçimleri değişken olmakla birlikte çoğu hastada sistemik kemoterapiye radyoterapi eklenmiştir ${ }^{20}$. Hasta grubumuzda ise iki kişide primer santral sinir sistemi lenfoması saptandı ve her ikisi de DBBHL tipindeydi. Bir hastada izole serebellum, diğerinde multipl parankimal tutulum vardı ve SOT-PTLH arası süre sırasıyla 1 ve 5 ylldı. Hastalardan biri 6 kür rituksimab ardından radyoterapi aldıktan sonra remisyonda izlenmektedir. Diğer hastaya RIDARAM tedavisi başlanmış ancak tedavinin erken döneminde sepsis nedeniyle kaybedilmiştir.

PTLH için standart bir tedavi yaklaşımı yoktur. Hastalığın türü, yaygınlığı ve hastanın performansı belirleyici olmaktadır. Sadece immunsupresif tedavinin azaltılmasıla remisyona giren olgular vardır ${ }^{21}$. SOT sonrası CD 20+ PTLH gelişen hastalara önce rituksimab (haftalık, toplam 4 hafta) ve 4 hafta sonra 3 kür CHOP tedavisi veren bir araștırma, bu ardışık tedaviyi etkili bulmuştur ${ }^{22}$. Hastalarımız immunsupresif tedavinin azaltılmasının yanında mutlaka sistemik bir tedavi de almışlardır. CD 20+ olan hastaların hepsi rituksimab alırken, klinik özelliklerine göre 3 hasta eş zamanlı kemoterapi de almıştır. HL hastaları klasik ABVD rejimi ile tedavi edilmiş, hastaların biri konsolidatif radyoterapi de almıştır. Hastaların hepsi ilk basamak tedavi sonrası remisyonda izlendiği için ikinci basamak tedavi alan hasta henüz yoktur.
Hastalarımızın 5 yıllık \%90 olan sağ kalımı, literatürde bildirilen birçok çalışmaya göre daha uzundur 12,13,23. Araştırmamız sakalım süresi açısından bir Japon çalışması ile benzerlik göstermektedir ${ }^{17}$.

Çalışmanın ana kısıtlılık nedeni az sayıdaki hasta ile yapılan, tek merkezli, retrospektif bir çalışma olmasıdır. Hastaların SOT tarihleri geniş bir dağılım sergilemekte, transplant oldukları merkezler farklılık göstermektedir. $\mathrm{Bu}$ nedenle primer hastalıkları, donör ile ilgili bilgiler, donör ve hastanın serolojik durumu, SOT sürecinin detayları ve rejeksiyon bilgileri kisitlıdır.

Çalışmada amacımız, bu heterojen ve komplike hasta grubuna hematolojik olarak yaklaşımımızı değerlendirmekti. PTLH ile baş ederken transplante organı korumak, zaten immunsuprese olan bu hastalara yeni bir kemoterapi vermek zor bir süreç olabilmektedir. Ancak erken dönemde septik nedenlerle kaybedilen bir hasta dışındaki hastalar hayatta ve remisyondadır. Hasta grubumuzun 5 yıllık sağ kalım oranı, literatürde bildirilen birçok çalışmadan daha uzun olması tedavi başarısını göstermektedir.

Çıkar Çatışması Beyanı: Yazarlar çıkar çatışması olmadığını bildirmişlerdir.

Finansal Destek: Bu çalışma her hangi bir fon tarafından desteklenmemiştir.

Declaration of Conflicting Interests: The authors declare that they have no conflict of interest.

Financial Disclosure: No financial support was received.

\section{KAYNAKLAR}

1. Adami J, Gäbel $H$, Lindelöf $B$, et al. Cancer risk following organ transplantation: a nationwide cohort study in Sweden. Br J Cancer 2003; 89: 1221.

2. Petrara MR, Giunco S, Serraino D, Dolcetti R, De Rossi A. Post-transplant lymphoproliferative disorders: from epidemiology to pathogenesis-driven treatment. Cancer Lett 2015; 369: 37-44. 
3. Ibrahim HA, Naresh KN. Posttransplant lymphoproliferative disorders. Adv Hematol 2012; 2012: 230173.

4. Opelz G, Naujokat C, Daniel V, Terness P, Döhler B. Disassociation between risk of graft loss and risk of non-Hodgkin lymphoma with induction agents in renal transplant recipients. Transplantation 2006; 81: 1227.

5. Shahinian VB, Muirhead N, Jevnikar AM, et al. EpsteinBarr virus seronegativity is a risk factor for late-onset posttransplant lymphoroliferative disorder in adult renal allograft recipients. Transplantation 2003; 75 : 851.

6. Zangwill SD, Hsu DT, Kichuk MR, et all. Incidence and outcome of primary Epstein-Barr virus infection and lymphoproliferative disease in pediatric heart transplant recipients. J Heart Lung Transplant 1998; 17: 1161.

7. Swerdlow SH, Campo E, Harris NL, et al. (Eds): WHO Classification of Tumours of Haematopoietic and Lymphoid Tissues (Revised 4th edition). lARC: Lyon 2017, p.453- 462.

8. Tsai DE, Hardy CL, Tomaszewski JE, et al. Reduction in immunosuppression as initial therapy for posttransplant lymphoproliferative disorder: analysis of prognostic variables and long-term follow-up of 42 adult patients. Transplantation 2001; 71: 1076.

9. Trappe $R$, Oertel $S$, Leblond $V$, et al. Sequential treatment with rituximab followed by CHOP chemotherapy in adult B-cell post-transplant lymphoproliferative disorder (PTLD): the prospective international multicentre phase 2 PTLD-1 trial. Lancet Oncol 2012; 13: 196-206.

10. Jagadeesh D, Woda BA, Draper J, Evens AM. Post transplant lymphoproliferative disorders: risk, classification, and therapeutic recommendations. Curr Treat Options Oncol 2012; 13: 122.

11. Evens AM, David KA, Helenowski I, et al. Multicenter analysis of 80 solid organ transplantation recipients with post-transplantation lymphoproliferative disease: outcomes and prognostic factors in the modern era. J Clin Oncol 2010; 20; 28: 1038-46.

12. Dierickx D, Tousseyn T, Sagaert X, et al. Single-center analysis of biopsy-confirmed posttransplant lymphoproliferative disorder: incidence, clinicopathological characteristics and prognostic factors. Leuk Lymphoma 2013; 54: 2433-40.

13. Kinch A, Baecklund E, Backlin C, et al. A populationbased study of 135 lymphomas after solid organ transplantation: The role of Epstein-Barr virus, hepatitis $\mathrm{C}$ and diffuse large B-cell lymphoma subtype in clinical presentation and survival. Acta Oncol 2014; 53: 669-79.
14. Ready E, Chernushkin K, Partovi N, et al. Posttransplant Lymphoproliferative Disorder in Adults Receiving Kidney Transplantation in British Columbia: A Retrospective Cohort Analysis. Can J Kidney Health Dis 2018; 1: 5: 1-12.

15. Cheson BD, Fisher RI, Barrington SF, et al. Recommendations for initial evaluation, staging, and response assessment of Hodgkin and non-Hodgkin lymphoma: The Lugano classification. J Clin Oncol 2014; 32: 3059-67.

16. Morton M, Coupes B, Roberts SA, et al. Epidemiology of posttransplantation lymphoproliferative disorder in adult renal transplant recipients. Transplantation 2013; 15: 95: 470-8.

17. Ishihara $H$, Shimizu $T$, Unagami $K$, et al. PostTransplant Lymphoproliferative Disorder in Kidney Transplant Recipients: A Single-Center Experience in Japan. Ther Apher Dial 2016; 20: 165-73.

18. Caillard S, Lelong C, Pessione F, Moulin B; French PTLD Working Group. Post-transplant lymphoproliferative disorders occurring after renal transplantation in adults: report of 230 cases from the French Registry. Am J Transplant 2006; 6: 2735-42.

19. Trofe J, Buell JF, Beebe TM, et al. Analysis of factors that influence survival with post-transplant lymphoproliferative disorder in renal transplant recipients: the Israel Penn International Transplant Tumor Registry experience. Am J Transplant 2005; 5: 775-80.

20. Cavaliere R, Petroni G, Lopes MB, Schiff D; International Primary Central Nervous System Lymphoma Collaborative Group. Primary central nervous system post-transplantation lymphoproliferative disorder: an International Primary Central Nervous System Lymphoma Collaborative Group Report. Cancer 2010; 15: 116: 863-70.

21. Dierickx D, Tousseyn T, Sagaert X, et al. Single-center analysis of biopsy-confirmed posttransplant lymphoproliferative disorder: incidence, clinicopathological characteristics and prognostic factors. Leuk Lymphoma 2013; 54: 2433-40.

22. Trappe R, Oertel $S$, Leblond V, et al. Sequential treatment with rituximab followed by CHOP chemotherapy in adult B-cell post-transplant lymphoproliferative disorder (PTLD): the prospective international multicentre phase 2 PTLD-1 trial. Lancet Oncol 2012; 13: 196-206.

23. Jain A, Nalesnik M, Reyes J, et al. Posttransplant lymphoproliferative disorders in liver transplantation: a 20-year experience. Ann Surg 2002; 236: 429-37. 